\title{
In Defense of the Epistemic Imperative
}

\begin{abstract}
Sample (2015) argues that scientists ought not to believe that their theories are true because they cannot fulfill the epistemic obligation to take the diachronic perspective on their theories. I reply that Sample's argument imposes an inordinately heavy epistemic obligation on scientists, and that it spells doom not only for scientific theories but also for observational beliefs and philosophical ideas that Samples endorses. I also delineate what I take to be a reasonable epistemic obligation for scientists. In sum, philosophers ought to impose on scientists only an epistemic standard that they are willing to impose on themselves.
\end{abstract}

\section{Keywords}

Epistemic Obligation, Problem of Unconceived Alternatives, Scientific Individualism

Park, Seungbae (2018). "In Defense of the Epistemic Imperative", Axiomathes 28 (4): 435446.

pdf: http://rdcu.be/IEbz

DOI: $10.1007 / \mathrm{s} 10516-018-9371-9$.

Seungbae Park

Division of General Studies

Ulsan National Institute of Science and Technology

Republic of Korea

Email: nature@unist.ac.kr

Homepages: http://nature.unist.ac.kr,

http://philpapers.org/profile/5452

\section{Introduction}

Suppose that there are several alternative theories. Scientists eliminate all of them except one, and then conclude that it is true. Are they justified in believing that it is true? Matthew Sample's (2015) answer is no. He presents an original argument to defend his answer, appealing to P. Kyle Stanford's (2006) problem of unconceived alternatives and to Richard Feldman's (2000) view about epistemic obligations. I argue that Sample's argument is incorrect, and that if it is correct, it refutes not only scientific theories but also observational beliefs and philosophical ideas that Sample accepts, such as the problem of unconceived alternatives and Feldman's view about epistemic obligations.

The outline of this paper is as follows. In Section 2, I explicate Sample's argument and expose intrinsic problems with it. In Section 3, I expose problems extrinsic to it, i.e., I assume for the sake of argument that it is correct and then elucidate its disastrous consequences for observational beliefs and philosophical ideas. In Section 4, I argue that under the pessimist framework, to contend that scientists have an obligation to propose new theories implies that they have the obligation to increase the chance that subsequent researchers will fail to obtain true theories. In Section 5, I delineate what I take to be a reasonable epistemic obligation for scientists. The main thesis of this paper is that philosophers of science ought not to hold scientists to an epistemic standard that they are not willing to hold themselves to. 


\section{Intrinsic Problems}

Suppose that some scientists eliminate rival theories from the possibility space of alternatives to arrive at a true theory. Are they justified in believing that the last theory in the chain of elimination process is true? Sample answers no, contending that they might have the epistemic obligation to show that scientists, in all periods of time, would agree with them that their theory is indeed the last one in the chain of elimination process. Obviously, they cannot fulfill such an obligation, so they ought not to believe that it is true. In short, unless scientists take the diachronic perspective on their theory, they are not justified in believing that it is true:

..scientists ought not believe a theory on the basis of a contextually contingent eliminative inference. In other words, the scientist should be able to distinguish between two scenarios: (1) situations where the last theory standing is, in all contexts, the only theory that explains the evidence; and (2) situations where the last theory standing is the last theory only because some contextual feature prevents scientists from conceiving of genuine alternatives. (Sample, 2015: 864)

For example, Aristotle might have had to fulfill the epistemic obligation to take the diachronic perspective on Aristotelian mechanics, i.e., to show that Newton, Einstein, and their successors would all agree with him that Aristotelian mechanics was the last theory in the chain of the elimination process. Obviously, he could not fulfill this excessively ponderous obligation. How could he take into account all the future mechanics and background assumptions of all of his successors? Since he could not fulfill this epistemic obligation, he should not have believed that Aristotelian mechanics was true. The same thing can be said about Newton, Einstein, and all of their successors. So Sample argues.

One might object that since scientists cannot take the diachronic perspective on their theories, it is wrong to attribute the epistemic obligation to them. Sample dismisses this objection, saying that although scientists cannot fulfill the epistemic obligation, they might still have it:

Notice that fulfilling this obligation requires, quite improbably, that scientists escape any contextually contingent constraints on their reasoning, including cultural assumptions, implicit bias, psychological limitations, and so on. If Feldman is correct, however, the simple inability of scientists to fully evade their situatedness does not entail that they have no obligation to do so. (Sample, 2015: 864)

Feldman (2000) observes that we have certain social obligations, even if we are unable to fulfill them. For example, physicians have the obligation to be on time for appointments with their patients, and police officers have the obligation to arrest criminals, even though they are unable to fulfill them on certain occasions due to their personal issues. Such obligations stem from their roles as physicians and police officers. Similarly, epistemic agents "might have certain epistemic obligations that are, strictly speaking, beyond their ability to fulfill" (Sample, 2015: 863). ${ }^{1}$ These epistemic obligations stem from their role as epistemic agents. It is wrong to deny that epistemic agents have these epistemic obligations on the grounds that they are unable to fulfill them. Sample calls Feldman's observation on social and epistemic obligations "a powerful insight" (2015: 863).

\footnotetext{
1 Note that Sample says not that epistemic agents have the epistemic obligations but that they might have the epistemic obligations. This difference is huge, as will become clear soon.
} 
Sample's argument can be summarized as follows. Scientists might have the epistemic obligation to take the diachronic perspective on their theories, even if they are unable to fulfill it. Since they cannot fulfill it, they ought not to believe that their theories are true. Let me henceforth call this argument the argument from the epistemic obligation.

What are we to make of the argument from the epistemic obligation? Obviously, it is fallacious. The premise is a possibility statement that scientists might have the epistemic obligation to take the diachronic perspective on their theories. By contrast, the conclusion is a normative statement that scientists ought not to believe that their theories are true. So what? David Hume (1888/1978: 469) famously pointed out that a normative statement is not deducible even from a descriptive statement, i.e., there is a wide gap between descriptive and normative statements. It follows that there is a much wider gap between possibility and normative statements (Park, 2017a: 31).

How would Sample reply to this objection? His answer can be inferred from his remarks that scientists should transcend their background assumptions, and that the "new induction," viz., Stanford's (2006) problem of unconceived alternatives, dictates that we judge scientists' reasoning in the way we judge the conduct of physicians and police officers:

Scientists are expected to make responsible use of concepts, constantly test their theoretical commitments, and transcend their cultural context. So perhaps, in applying the "new induction," we judge past scientists' reasoning in the same way that we judge the conduct of a physician or of a police officer; we hold them accountable to the obligations of their role, regardless of their own (possibly unavoidable) limitations. (Sample, 2015: 865)

Given that Sample claims that scientists are on a par with physicians and police officers in terms of obligations, he would replace his possibility premise with the normative premise that scientists have the obligation to take the diachronic perspective on their theories. He would justify this new premise by constructing an argument from analogy that just as physicians and police officers have social obligations, so scientists have the epistemic obligation.

How strong is this argument from analogy? It depends on the strength of the analogy between the epistemic obligation of scientists and the social obligations of physicians and police officers. In my view, the analogy is weak. Physicians and police officers often fulfill their social obligations, although they sometimes do not, which indicates that it is typically feasible for them to fulfill their social obligations, and hence that it is reasonable to attribute those obligations to them. By contrast, it is infeasible for scientists to fulfill the epistemic obligation to take the diachronic perspective on their theories. How can they, or anyone, transcend their background assumptions? Imagine that Aristotle conceived of Newtonian mechanics and all the background assumptions that Newton relied on. Aristotle would then have had the new epistemic obligation, viz., to conceive of Einsteinian mechanics and all the background assumptions that Einstein relied on. Thus, the epistemic obligation that Sample imposes upon scientists is one that only God can fulfill.

Sample would retort that the inability of scientists to fulfill the epistemic obligation does not mean that they do not have it. The point is granted, but the inability does not mean either that they do have it. A positive argument is required to show that scientists have the epistemic obligation. Feldman's view about epistemic obligations only opens the possibility that scientists might have the epistemic obligation, and as we seen above, the mere possibility proves nothing.

It is easy to show that physicians and police officers have social obligations, but it is not so easy to show that scientists have the epistemic obligation. Physicians and police officers have signed contracts with their hospitals and governments, through which they get 
paid for fulfilling and punished for neglecting their social obligations. These contracts are sources of their social obligations. But what is the source of the epistemic obligation of scientists? They did not sign any contract giving rise to the epistemic obligation. Since the source of the epistemic obligation is not clear, there is no reason to think that scientists have the epistemic obligation. Thus, the aforementioned analogy is weak. It is one thing that physicians and police officers have their social obligations; it is another that scientists have the alleged epistemic obligation.

Sample might now forgo Feldman's view of epistemic obligations, and appeal only to the problem of unconceived alternatives, saying that Stanford "is leveraging our contemporary understanding of the duties of scientists" (Sample, 2015: 865). That is, Sample might now say that he has merely exposed the epistemic obligation implicit in the problem of unconceived alternatives. Aristotelian mechanics was replaced by Newtonian mechanics, which Aristotle could not entertain. This historical fact alone shows that Aristotle had the epistemic obligation to take the diachronic perspective on his theory, and the same can be said about all of his scientific offspring. Thus, exempting scientists from the epistemic obligation requires refuting the problem of unconceived alternatives.

Unfortunately, it requires separate papers to refute the problem of unconceived alternatives. This paper only summarizes Park's (2018) objection to it. He calls the problem of unconceived alternative the new pessimistic induction. The new pessimistic induction contrasts with the old pessimistic induction (Hesse, 1976: 266; Laudan 1977: 126; Putnam, 1978: 25). The old pessimistic induction is a pessimistic induction over scientific theories, asserting that the downfall of present theories can be inferred from the downfall of past theories. In contrast, the new pessimistic induction is the pessimistic induction over scientists, asserting that the inability of present scientists to conceive of future theories can be inferred from the inability of past scientists to conceive of present theories. The intense debate over the old pessimistic induction revealed that it has several problems that were theretofore hidden when it was formulated in the 1970s. For example, it overlooks the fact that present theories are more successful than past theories. On the basis of this observation, Park concludes that it has infinitely many heretofore hidden problems. He goes further, maintaining that since the old pessimistic induction has infinitely many hidden problems, the new pessimistic induction also has infinitely many hidden problems. Therefore, we should shake off the infinitely problematic intuitions that since Aristotelian mechanics and Newtonian mechanics turned out to be false, Einsteinian mechanics will also turn out to be false, and that since Aristotle and Newton could not imagine the subsequent theories that would displace their theories, Einstein too could not imagine the alternative theory that will displace his theory. Park calls his pessimistic induction from the old pessimistic induction to the new pessimistic induction the grand pessimistic induction. The grand pessimistic induction reflects Stanford's problem of unconceived alternatives, according to which there are infinitely many unconceived alternatives, so scientists cannot arrive at true theories no matter how many false theories they may eliminate from the possibility spaces of alternatives.

\section{Extrinsic Problems}

This section sets aside the criticisms that I have leveled at Sample's argument from the epistemic obligation in the previous section, assumes for the sake of argument that Sample's argument is correct, and elucidates its disastrous consequences that Sample would find unacceptable.

Consider the observational belief that snow is white. How would our distant descendants evaluate this belief? It is not clear what the correct answer to this question is. 
Genetic mutations might occur. As a result, snow might not appear to be white to them. We (might) have the epistemic obligation to take the diachronic perspective on this current observational belief. Since we cannot fulfill it, we ought not to believe that it is true, i.e., that snow is white.

Even Feldman's powerful insight falls prey to Sample's argument from the epistemic obligation. Feldman contends that epistemic agents might have certain epistemic obligations, even though they cannot fulfill them. Is this contention true? Sample says yes. Epistemic agents, however, (might) have the epistemic obligation to take the diachronic perspective on Feldman's contention. Since they cannot fulfill it, they ought not to believe that Feldman's contention is true.

Sample (2015: 861) advanced the argument from the epistemic obligation to defend the problem of unconceived alternatives from critics, such as P. D. Magnus (2006). The problem of unconceived alternatives, however, is also susceptible to Sample's argument. Stanford and Sample (might) have the epistemic obligation to take the diachronic perspective on the problem of unconceived alternatives, i.e., to show that philosophers of all ages would accept it. Since they cannot fulfill the epistemic obligation, they ought not to believe that the problem of unconceived alternatives is correct. Keep in mind that not only scientists but also philosophers, including Stanford and Sample, are restricted to their background assumptions.

Stanford (2006: 195) embraces instrumentalism after wielding the problem of unconceived alternatives against scientific realism. Instrumentalism, however, is also vulnerable to Sample's argument from the epistemic obligation. Instrumentalists take the instrumentalist attitude towards our best current theories. They, however, (might) have the epistemic obligation to take the diachronic perspective on instrumentalism, i.e., to show that philosophers of all times would approve of it. Since they cannot fulfill the epistemic obligation, they ought not to take the instrumentalist attitude towards our best current theories.

Such criticisms against philosophical ideas can be extended ad nauseam. To avoid this unsavory consequence, Sample might appeal to the criticisms that I launched against his argument in the previous section. For example, he might now say that scientists do not have the epistemic obligation to take the diachronic perspective on their theories, although doctors and police officers have the social obligations to cure patients and arrest criminals, respectively. If he says so, however, he can no longer say that scientists ought not to believe that their theories are true.

Objectors might now argue that science and philosophy should be judged by different standards, so that Sample's argument from the epistemic obligation applies to science, but not to philosophy. Thus, scientists have the epistemic obligation to take the diachronic perspective on scientific theories, whereas philosophers do not have the epistemic obligation to take the diachronic perspective on philosophical ideas.

Saying so, however, manifests philosophical arrogance, giving the impression that philosophers have epistemic access to true philosophical theories, even if they do not take the diachronic perspective on them, whereas scientists do not have epistemic access to true scientific theories unless they take the diachronic perspective on them. The arrogance also gives the impression that philosophers have not made mistakes in the history of philosophy, whereas scientists have made mistakes in their history, which is clearly false. Just think about Plato's theory of Forms and Descartes's substance dualism. Philosophers made so many mistakes in the history of philosophy that Moti Mizrahi (2016) constructs a pessimistic induction from past to present philosophical theories, including scientific antirealism.

Some might argue that there are cases in which the criticism or application of a view 
does not apply to itself. ${ }^{2}$ For example, consider cases of peer disagreement in which conciliationists think that conciliationism should not apply at the meta-disagreement between conciliationists and steadfasters. Thus, exceptions are allowed, and perhaps that might be argued in the case of philosophical arguments and scientific theorizing.

This critical response is perhaps the most reasonable one to my objection that Feldman's powerful insight is subject to Sample's argument from the epistemic obligation. My rejoinder is to point out that it is merely an assumption that we (might) have certain epistemic obligations that are beyond their ability to fulfill, and that one way to determine whether it is tenable or not is, if Sample is right, to think about whether our descendants will accept or reject it. What is so special about Feldman's assumption that makes it an exception to the general claim that we should take the diachronic perspective on ideas?

To use an analogy, suppose that you see a black swan in front of you, so you have the perceptual evidence for the belief that the swan in front of you is black. The evidence entitled you to believe that the swan in front of you is an exception to the general claim that all swans are white. Similarly, suppose that we have somehow the evidence for Feldman's assumption. The evidence would entitle us to believe that his assumption is an exception to the general claim that we should take the diachronic perspective on ideas. It is not clear, however, what the evidence is, so it is not clear why his assumption is an exception to the general claim.

Let me draw a philosophical moral from the discussion so far. Philosophers of science ought not to impose on scientists an epistemic obligation that they are not willing to impose on themselves. This proposal leads us to what I call the epistemic imperative: Act only on an epistemic maxim through which you can at the same time will that it should become a universal one. Epistemic maxims are rules related to epistemic matters, such as "Take the diachronic perspective on ideas" and "Other things being equal, choose a simple theory."

The epistemic imperative parallels Kant's categorical imperative: "Act only on that maxim through which you can at the same time will that it should become a universal law" (Kant, 1964: 35). The categorical imperative originates from the observation that we tend to be lenient on ourselves, but harsh on others, concerning moral matters. Similarly, the epistemic imperative originates from the observation (Park, 2017a: 34) that some scientific antirealists tend to criticize scientific realism without realizing that their brilliant criticisms apply no less to their own positive philosophical views.

As an example, Bas van Fraassen (1980: 72-73, 1985: 294) wields the principle of economy against scientific realism, and van Fraassen (1989: 143-146) criticizes inference to the best explanation. As Park (2017b: 60-62) observes, however, van Fraassen (1980: Chapter 5) claims that his contextual theory of scientific explanation is true on the grounds that it explains some explanatory phenomena in science, such as rejections and asymmetries, whereas the rival theories of scientific explanation cannot. Obviously, the principle of economy and his critiques of inference to the best explanation apply with as much force to the contextual theory of scientific explanation. On this account, Sample is on the same boat as van Fraassen. Sample's argument from the epistemic obligation backfires on the problem of unconceived alternatives and Feldman's view about epistemic obligations that he appeals to.

Why should we abide by the epistemic imperative? ${ }^{3}$ Not observing it comes with costs. Imagine that you reject your epistemic colleagues' theories, imposing an inordinately high standard on them. You, however, say to them that they should accept your theories without

\footnotetext{
${ }^{2}$ I thank an anonymous referee for this criticism.

${ }^{3}$ I thank the anonymous referee for this question.
} 
imposing it on your theories. How would your epistemic colleagues respond to you? They might ostracize you, thinking that you are a selfish and unfair epistemic agent. Or they might impose the excessively high standard on your theories, and say to you that you should not impose it on their theories. They have embraced epistemic reciprocalism, the view that "we ought to treat our epistemic colleagues, as they treat their epistemic colleagues" (Park, 2017b: $57)$.

\section{Ruining Future Research}

Sample claims that Stanford's problem of unconceived alternatives has the philosophical significance of revealing that scientists of $T_{1}$ have the epistemic obligation to ideate $T_{2}$, and that scientists of $T_{2}$ have the epistemic obligation to ideate $T_{3}$, and so forth, where $T_{1}, T_{2}$, and $\mathrm{T}_{3}$ are successive theories:

Specifically, we can interpret Stanford's analyses of past research (e.g. that Darwin ought to have thought of the alternative mode of gemmules diffusions, that Kant ought to have considered relativistic physics) in terms of backwards-looking normative judgments. Though they originate in the norms of a community, we impose these epistemic obligations on individuals, on anyone who appears to take on the role of scientist. (Sample, 2015: 865)

This epistemic obligation is less demanding than the epistemic obligation to take the diachronic perspective on scientific theories, which requires considering all the accepted theories and background assumptions in the entire development of science.

In my view, however, it is unreasonable to impose even this less demanding obligation on scientists. According to the old and new pessimistic inductions, just as $T_{1}$ is fated to be abandoned, so $\mathrm{T}_{2}$ is fated to be abandoned. On the pessimist account, "what comes after trials and errors are only other trials and errors" (Park, 2017c: 218). More importantly, the downfall of $\mathrm{T}_{1}$ constitutes an inductive rationale for expecting that of $\mathrm{T}_{2}$. The more theories are overthrown, the stronger the inductive rationale becomes for thinking that next theory will be overthrown. So, for example, it is more likely that Einsteinian mechanics will be overturned than it was that Newtonian mechanics would be overturned. After all, Einsteinian mechanics has more discarded predecessors than Newtonian mechanics had. To use an analogy, if you observed two black crows whereas I observed one black crow, your inductive rationale is stronger than mine for thinking that the next crow to be observed will be black. To reject this analogy is to reject both the old and new pessimistic inductions.

Let me turn back to the less demanding epistemic obligation. Saying that theorists of $T_{n}$ have the epistemic obligation to conceive of $T_{n+1}$ is tantamount to saying that they have the obligation to increase the inductive rationale for expecting the downfall of the next theories, i.e., they have the obligation to dampen their successors' aspiration to obtain truths. Do scientists have such an obligation? Sample has no choice but to say yes, given that he operates under the problem of unconceived alternatives, and that he states explicitly that Stanford "is leveraging our contemporary understanding of the duties of scientists" (2015: 865). Of course, Stanford did not intend the problem of unconceived alternatives to have this absurd consequence. Nor did Sample intend his view of epistemic obligation to have this absurd consequence. But the absurd consequence follows jointly from his suggestion that theorists of $T_{n}$ have the epistemic obligation to conceive of $T_{n+1}$ and from Stanford's suggestion that the demise of past theories constitutes an inductive rationale for expecting the demise of present theories.

\section{Scientific Individualism}


I have argued that Sample's argument from the epistemic obligation imposes an inordinately heavy epistemic obligation on scientists. What, then, would be a reasonable epistemic obligation for scientists? This question can be answered from the perspective of scientific individualism.

According to scientific individualism (Park, 2017d: 99), the unit of evaluation in the scientific realism debate should not be a set of theories but an individual theory. Scientific individualism contrasts with scientific collectivism according to which the unit of evaluation is not an individual theory but a set of theories. Individualists take epistemic attitudes towards each single theory, depending on their evaluation of scientists' arguments for it. If they think that the arguments are strong, they believe that it is true. If they think that the arguments are weak, they do not believe that it is true. In contrast, collectivists take epistemic attitudes towards a group of theories, depending on their evaluation of philosophical arguments, such as the pessimistic and selective inductions.

What are the pessimistic and selective inductions? The pessimistic induction holds that the downfall of present theories can be extrapolated from the downfall of past theories. The selective induction holds that the transmission of some theoretical assumptions from present to future theories can be extrapolated from the transmission of some theoretical assumptions from past to present theories (Worrall, 1989; Kitcher, 1993: Chapters 4 and 5; Psillos, 1999: Chapter 6; Chakravartty, 2008; Enfield, 2008; Harker, 2008; Psillos, 2009; Saatsi, 2009; Vickers, 2016). Both the pessimistic and selective inductions presuppose that past, present, and future theories should be evaluated collectively.

An example will illustrate the distinction between individualism and collectivism. Suppose that $T_{1}, T_{2}$, and $T_{3}$ are successive theories. Pessimistic collectivists believe that just as $\mathrm{T}_{1}$ was falsified, so $\mathrm{T}_{2}$ will be falsified. Selective collectivists believe that just as some theoretical assumptions were preserved from $\mathrm{T}_{1}$ to $\mathrm{T}_{2}$, so some theoretical assumptions will be preserved from $T_{2}$ to $T_{3}$. They claim that we are justified in believing that the common theoretical assumptions are true, but not in believing that the other theoretical assumptions are true. Both pessimistic and selective collectivists believe that the epistemic status of $\mathrm{T}_{3}$ depends on the epistemic status of its predecessors, $T_{1}$ and $T_{2}$, so we need to take $T_{1}$ and $T_{2}$ into account in order to determine our epistemic attitude towards $\mathrm{T}_{3}$.

By contrast, individualists believe that the epistemic status of $\mathrm{T}_{3}$ is independent of the epistemic status of $\mathrm{T}_{1}$ and $\mathrm{T}_{2}$. Individual realists believe that $\mathrm{T}_{3}$ is true in toto, even if no part of $T_{1}$ and $T_{2}$ survived scientific revolutions, insofar as they think that scientists' arguments for $T_{3}$ are strong. In addition, individual antirealists believe that no part of $T_{3}$ is true, even if most parts of $T_{1}$ and $T_{2}$ had survived scientific revolutions, as long as they think that scientists' arguments for $\mathrm{T}_{3}$ are weak. If individualists believe that some theoretical assumptions of $\mathrm{T}_{3}$ are true, that is not because the theoretical assumptions are inherited from $\mathrm{T}_{1}$ and $\mathrm{T}_{2}$ but because scientists' arguments strongly support them.

Individualism yields an answer to the question of what epistemic obligation it is reasonable to attribute to scientists. Scientists have the epistemic obligation to evaluate their arguments for a theory to determine their epistemic attitudes towards it. They do not have the epistemic obligation to take the diachronic perspective on it, i.e., they do not need to consider how scientists in other periods of time would think of it. They are justified in believing that a theory is true, even if their descendants might think that it is false, insofar as their arguments for it are strong. They are justified in refusing to believe that it is true, even if their descendants might think that it is true, as long as their arguments for it are weak. In short, scientists have the epistemic obligation to determine their epistemic attitudes towards their theories exclusively in accordance with their appraisal of their arguments for them. 
Philosophical arguments, such as the pessimistic and selective inductions, are irrelevant to the evaluations of scientific theories.

Individualists are happy to comply with the epistemic imperative. In general, philosophers accept or reject a philosophical theory, depending on whether they think that the arguments for it are strong or weak. They do not accept or reject it, depending on whether they think that philosophers in other eras would agree with them or not. Nor do they accept or reject it, depending on whether the pessimistic induction against it and the selective induction for it are strong or weak. For example, epistemologists do not say that since foundationalism and coherentism were abandoned, reliabilism (Goldman, 1979, 1992) will also be abandoned. Nor do they say that only the common assumptions of the three theories of epistemic justification are trustworthy. They accept or reject reliabilism, depending exclusively on whether reliabilists' arguments for it are strong or weak. The epistemic imperative requires that just as individualists accept or reject a scientific theory, depending on how they evaluate scientists' arguments for it, so too they should accept or reject reliabilism, depending on how they evaluate reliabilists' arguments for it. This requirement is a welcome one from the perspective of individualists. After all, meeting it means that they follow the general epistemic practice of epistemologists and most other philosophers, but not the epistemic practice of Sample, pessimists, and selectivists.

\section{Conclusion}

Sample appeals to Stanford's problem of unconceived alternatives and Feldman's view about epistemic obligations, arguing that scientists (might) have the epistemic obligation to take a diachronic perspective on their theories, and that since they cannot fulfill it, they ought not to believe that their theories are true. I made some criticisms against Sample's argument from the epistemic obligation. The most important one is that philosophers of science ought to attribute only epistemic obligations to scientists that they are willing to attribute to themselves. In sum, we ought to comply with the epistemic imperative: Act only on an epistemic maxim through which you can at the same time will that it should become a universal one.

\section{References}

Chakravartty, Anjan (2008). "What You Don't Know can't Hurt You: Realism and the Unconceived", Philosophical Studies 137 (1): 149-158.

Enfield, Patrick (2008). Review of P. Kyle Stanford's Exceeding Our Grasp: Science, History, and the Problem of Unconceived Alternatives, The British Journal for the Philosophy of Science 59 (4): 881-895.

Feldman, Richard (2000). "The Ethics of Belief", Philosophy and Phenomenological Research 60 (3): 667-695.

Goldman, Alvin (1979). "What Is Justified Belief?", In Justification and Knowledge. George Pappas (ed.), Boston: D. Reidel Publishing Company: 1-23.

(1992). "Epistemic Folkways and Scientific Epistemology" in Alvin Goldman (ed.), Liaisons: Philosophy Meets the Cognitive and Social Sciences. MA: MIT Press: 49-66. 
Harker, David (2008). "P. Kyle Stanford, Exceeding Our Grasp: Science, History, and the Problem of Unconceived Alternatives", Philosophy of Science 75 (2): 251-253.

Hesse, Mary (1976). "Truth and the Growth of Scientific Knowledge", PSA: Proceedings of the Biennial Meeting of the Philosophy of Science Association 2: 261-280.

Hume, David. (1888/1978) A Treatise of Human Nature. L. A. Selby-Bigge and P. H. Nidditch (eds.), Oxford: Oxford University Press.

Kant, Immanuel (1964). Groundwork of the Metaphysics of Morals, trans. H.J. Paton, New York: Harper \& Row.

Kitcher, Philip (1993). The Advancement of Science: Science without Legend, Objectivity without Illusion. New York: Oxford University Press.

Laudan, Larry (1977). Progress and Its Problems: Towards a Theory of Scientific Growth. California: University of California Press.

Magus, P. D. (2006). “What's New about the New Induction?” Synthese 148 (2): 295-301.

Mizrahi, Moti (2016). "Historical Inductions, Unconceived Alternatives, and Unconceived Objections", Journal for General Philosophy of science 47 (1): 59-68.

Park, Seungbae (2017a). "Scientific Antirealists Have Set Fire to Their Own Houses", Prolegomena 16 (1): 23-37. 64. (2017b). “Defense of Epistemic Reciprocalism”, Filosofija. Sociologija 28 (1): 56(2017c). "The Uniformity Principle vs. the Disuniformity Principle", Acta Analytica 32 (2): 213-222.

(2017d). "Selective Realism vs. Individual Realism for Scientific Creativity", Creativity Studies 10 (1): 97-107.

$7-19$.

(2018). “The Grand Pessimistic Induction”, Review of Contemporary Philosophy 17:

Psillos, Stathis (1999). Scientific Realism: How Science Tracks Truth. New York: Routledge.

-------- (2009). “Grasping at Realist Straws”, Review Symposium, Metascience 18: 363370.

Putnam, Hilary (1978). Meaning and the Moral Sciences. London: Routledge \& K. Paul.

Saatsi, Juha (2009). "Grasping at Realist Straws”, Review Symposium, Metascience 18: 355362. 
Sample, Matthew (2015). "Stanford's Unconceived Alternatives from the Perspective of Epistemic Obligations", Philosophy of Science 82 (5): 856-866.

Stanford, P. Kyle (2006). Exceeding Our Grasp: Science, History, and the Problem of Unconceived Alternatives. Oxford: Oxford University Press.

van Fraassen, Bas (1980). The Scientific Image. Oxford: Oxford University Press.

(1985). "Empiricism in the Philosophy of Science", In Images of Science. Paul Churchland and Clifford Hooker (eds.), Chicago: The University of Chicago Press.

-------- (1989). Laws and Symmetry. Oxford: Oxford University Press.

Vickers, Peter (2016). "Understanding the Selective Realist Defence against the PMI", Synthese. doi:10.1007/s11229-016-1082-4.

Worrall, John (1989). "Structural Realism: The Best of Both Worlds", Dialectica 43: 99-124. 